\title{
Comunicação
}

(Communication)

\section{Duração da gestação e do parto em éguas Puro Sangue Árabe}

[Length of gestation and parturition in Arabian Thoroughbred mares]

\author{
M. Valente ${ }^{1}$, M.M. Unanian $^{2}$, A.B.S. Villarroel ${ }^{3}$, F.F.F. Gomes ${ }^{4}$ \\ ${ }^{1}$ Faculdade Tecnológica-CENTEC - Sertão Central \\ ${ }^{2}$ Médica Veterinária autônoma \\ ${ }^{3}$ Departamento de Zootecnia - CCA - UFC - Fortaleza, CE \\ ${ }^{4}$ Aluna de Graduação - UFC - Fortaleza, CE
}

A duração da gestação é afetada por fatores genéticos, climáticos e nutricionais (CrowellDavis e Houpt, 1986). Na espécie eqüina, a duração da gestação varia entre raças e indivíduos da mesma raça. O manejo também pode ser responsável por essa variação. A idade da égua e o sexo da cria foram apontados como fatores que influenciam a duração da gestação (Ropiha et al., 1969). Na raça Árabe, foram descritos valores mínimos de duração da gestação de 330,0 dias (Ponomarenko, 1991) e máximos de 341,7 dias (Vivo et al., 1984). No Brasil, Unanian e Pereira (1991), ao estudarem a duração da gestação em 23 éguas da raça Puro Sangue Inglês e em 20 Árabe cruzadas, observaram médias de $330 \pm 6,35$ (307 a 363) e $337,5 \pm 2,47$ (317 a 361), respectivamente.

O parto é um evento importante dentro do ciclo reprodutivo, especialmente em animais que apresentam prenhez longa, como os eqüinos. Os valores descritos na literatura para duração do parto diferem entre as várias raças. Segundo Unanian (1991), a duração média do parto foi de 30 minutos em éguas Árabe e 56 minutos em fêmeas Árabe cruzadas.
Os partos em éguas domesticadas ocorrem preferencialmente à noite, talvez porque $\mathrm{o}$ distúrbio pela presença humana é mínimo (Tyler, 1972). Entre éguas Puro Sangue Inglês (PSI), os partos ocorrem preferencialmente entre 19 e 7 horas $(86 \%)$, com máxima incidência entre 22 e 23 horas (Rossdale e Short, 1967; Rossdale, 1968b). Ainda nessa raça, Bain e Howey (1975) observaram 1.185 partos, dos quais $83,6 \%$ foram à noite. Tyler (1972) relatou que a maioria dos nascimentos entre pôneis New Forest semiselvagens ocorreu ainda no escuro, durante a madrugada. Cavalos selvagens asiáticos também parem à noite, mesmo em zoológicos (Mohr, 1971), diversamente dos cavalos selvagens do Deserto Americano do Wyoming, que pariram durante o dia quando em liberdade absoluta ou mesmo depois de adotados (Boyd, 1980).

Considerando a importância do conhecimento dessas características e o fato de que no Brasil existem poucos estudos na espécie eqüina, realizou-se este trabalho com o objetivo de estudar a duração da gestação e do parto e o horário do parto em éguas da raça Árabe.

Recebido em 26 de maio de 2004

Aceito em 23 de março de 2006

*Endereço para correspondência (mailing address)

Rua Rafael por Deus, 65

63.800-000 - Quixeramobim, CE

E-mail: zambs9@hotmail.com 
Foram estudadas 147 gestações ocorridas durante 10 anos, em um rebanho de éguas da raça Árabe, regularmente mantidas em pastagem de coastcross (Cynodon dactylon). As éguas foram classificadas segundo a idade em: jovens $(\leq 4$ anos), adultas (5 a 9 anos) e velhas ( $\geq 10$ anos), ou primíparas e multíparas, segundo a ordem de parição. O período de gestação foi estimado considerando o intervalo entre o último dia de serviço (data da última cobrição ou inseminação artificial) e a data do parto.

A duração e o horário do parto foram estudados em 12 éguas, com idade entre 4 e 19 anos de idade. Para observação dos partos, os animais foram alojados durante a noite em baias individuais de $25 \mathrm{~m}^{2}$, em um galpão com iluminação fraca. A duração do parto foi medida a partir da ruptura do alantocórion até a expulsão da placenta, sendo dividido em: primeira fase, correspondente ao período antes da ruptura das membranas fetais, segunda fase, da ruptura do alantocórion até a expulsão do feto e terceira fase, correspondendo ao intervalo entre a expulsão total do feto e a expulsão da placenta.

Os dados foram analisados quanto à duração da gestação em função da idade e da ordem de parição dos animais e do sexo do produto, utilizando o programa SPSS/PC+ (Snedecor e Cochran, 1967).

A estatística descritiva do parto mostrou sua duração média e de cada uma das fases e o horário de ocorrência dos partos.

A duração média da gestação das éguas foi de $330,42 \pm 9,89$ dias, confirmando os resultados para a raça no Brasil (Unanian, 1991), porém ligeiramente inferior à maioria das informações obtidas em outros países: 332,1 $\pm 3,3$ dias (ElWishy et al., 1990), 335,84 $\pm 0,46$ (Dermici, 1988 ) e $341,7 \pm 10$ dias (Vivo et al., 1984). Essas diferenças entre animais da mesma raça podem ser explicadas principalmente por fatores ambientais.

A análise de variância mostrou que houve influência da idade sobre a duração da gestação (Tab. 1). A duração da gestação de éguas com até quatro anos de idade foi mais longa do que a de éguas mais velhas $(\mathrm{P}<0,05)$. Segundo a metodologia usada para o agrupamento das éguas em função da idade, estes resultados poderiam indicar diferença entre a duração da gestação de éguas primíparas e multíparas, uma vez que o último grupo foi constituído de éguas adultas e velhas. Assim, a duração da gestação foi maior nas primíparas, segundo a regressão:

$y=335,29-0,52 \times$, em que:

$\mathrm{x}=$ idade da égua e $\mathrm{y}=$ duração da gestação.

Tabela 1. Duração da gestação (média \pm desviopadrão) em éguas da raça Puro Sangue Árabe, em função da idade

\begin{tabular}{lcc}
\hline Faixa etária & N. $^{\circ}$ animais & Duração da gestação \\
\hline Jovens $(\leq 4$ anos $)$ & 23 & $335,00 \pm 8,90 \mathrm{a}$ \\
Adultas $(5 \leq \mathrm{x} \leq 9$ anos $)$ & 66 & $330,56 \pm 11,98 \mathrm{~b}$ \\
Velhas $\geq 10$ anos $)$ & 58 & $328,45 \pm 6,59 \mathrm{~b}$ \\
\hline Valores seguidos por letras distintas na mesma coluna \\
diferem entre si $(\mathrm{P}<0,05)$ pelo teste $t$.
\end{tabular}

Observou-se correlação negativa $(\mathrm{r}=-0,24 ; \mathrm{P}=$ 0,002 ) entre a idade da égua e a duração da gestação, resultado semelhante ao obtido por Dermici (1988) $(\mathrm{r}=-0,25 ; \mathrm{P}<0,05)$, que também observou decréscimo na duração da gestação com aumento da idade. Todavia, Flade e Frederich (1963), citados por Ropiha et al. (1969), observaram em animais jovens, com até três anos de idade, uma duração da gestação mais curta do que em animais mais velhos. A maior duração de gestação em éguas jovens pode estar associada à distribuição dos recursos biológicos disponíveis entre a gestação e o término de desenvolvimento corporal da égua, o que resultaria na necessidade da permanência mais longa do feto no útero materno, até atingir o desenvolvimento fisiológico necessário ao nascimento.

Não houve diferença na duração da gestação em razão do sexo da cria (Tab. 2), resultado também observado em éguas da mesma raça por Vivo et al. (1984), Dermici (1988) e El-Wishy et al. (1990).

Tabela 2. Duração da gestação (média \pm desvio padrão) das éguas da raça Puro Sangue Árabe, em função do sexo da cria

\begin{tabular}{lcc}
\hline $\begin{array}{l}\text { Sexo da } \\
\text { cria }\end{array}$ & $\begin{array}{c}\text { Duração da } \\
\text { gestação }\end{array}$ & $\begin{array}{c}\text { Coeficiente } \\
\text { de variação }\end{array}$ \\
\hline Macho & $330,40 \pm 09,05$ & $2,7 \%$ \\
Fêmea & $330,44 \pm 10,52$ & $3,2 \%$ \\
\hline
\end{tabular}


A duração média do parto foi de 55,64 minutos, sendo maior do que os 30 minutos relatados por Unanian e Pereira (1991). A duração da primeira fase do parto (2,3 minutos) foi diferente do observado por Rossdale (1968b) e Rossdale e Ricketts (1979) em éguas da raça PSI (até quatro horas). O tempo transcorrido na segunda fase do parto (11 minutos) coincidiu com o descrito por Rossdale (1968a) e Rossdale e Ricketts (1979). A terceira fase do parto durou, em média, 42 minutos e esteve dentro do intervalo de até seis horas pós-parto proposto como limite após o qual se caracteriza retenção da placenta (Unanian, 1991).

Os partos ocorreram predominantemente no período noturno, sendo $36,4 \%$ entre 20 e 24 horas e $63,6 \%$ entre zero e 4 horas, semelhante ao relatado por Rossdale e Short (1967) e Bain e Howey (1975) para o PSI e, ainda, por Tyler (1972) e Mohr (1971), em cavalos semiselvagens e selvagens. Neste trabalho ocorreu apenas um parto durante o dia, considerado distocíaco.

Parece haver um forte ritmo circadiano em eqüinos, segundo o qual o parto está concentrado nas horas de escuridão ou de luz reduzida. Rossdale (1968b), ao estudar 655 nascimentos, observou apenas 33 ocorridos entre 10 e 16 horas. Segundo o autor, isso sugere que nem a fêmea nem o produto envolvidos no nascimento diurno não estariam em desvantagem se comparados com aqueles que seguem o padrão mais usual. Embora mecanismos estejam envolvidos no processo de concentração de nascimentos nas horas de escuridão, segundo Rossdale (1968b), não há presumivelmente um significado adaptativo desse comportamento sob condições de manejo moderno. Rossdale e Ricketts (1979) e Crowell-Davis e Houpt (1986) relataram existir uma possível interferência da hipófise no controle materno da hora do parto, o que confirma a observação de autores que acreditam que, se as fêmeas forem perturbadas, $o$ processo de parto pode ser retardado em muitas horas (Klingel, 1969 e Houpt, 1977, citados por Boyd, 1980) e ocorreria à noite, possivelmente porque esse é o horário de menor interferência humana (Tyler, 1972).

Conclui-se que a determinação de uma equação de regressão, com base nos dados de cada rebanho eqüino, seria uma ferramenta importante para a previsão e o acompanhamento do parto.

Palavras-chave: eqüino, gestação, parto

\begin{abstract}
The length of gestation and parturition in 147 Arabian Thoroughbred mares were studied. Length of gestation averaged 330 days and was influenced by the age of mare. They were 335, 330 and 328 days for mares aged up to 4 years, 5 to 9 years and over 10 years, respectively. Parturition lasted 56 minutes on average and was not influenced by the reproductive condition of the mare. Most births occurred at night.
\end{abstract}

Keywords: gestation, parturition, equine

\section{REFERÊNCIAS BIBLIOGRÁFICAS}

BAIN, A.M.; HOWEY, W.P. Observations on the time of foaling in Thoroughbred mares in Australia. J. Reprod. Fertil., suppl. 23, p.545546. 1975.

BOYD, L.E. The natality, foal survivorship, and mare-foal behavior of feral horses in wyoming's red desert. 1980. Thesis (Master Degree) University of Wyoming, WI.

CROWELL-DAVIS, S.L.; HOUPT, K.A.
Maternal behaviour. Vet. Clin. North. Am., v.2, p.557-571, 1986.

DERMICI, E. Length of gestation in purebred Arab mares and the effect of age on gestation length. Vet. Fak. Reprod., v.35, p.69-79, 1988.

EL-WISHY, A.B.; EL-SAYED, M.A.I.; SIDA, A.A. et al. Some aspects of reproductive performance in Arabian mares in Egypt. Reprod. Dom. Anim., v.25, p.227-234, 1990.

FLADE, J.E.; FREDERICH, W. Untersuchungen über die Trächtigheitsdauer der Stuten. Arch. für 
Tierzocht, v. 6, p. 505, 1963.

HOUPT, K.A. Horse Behaviour: its relevance to the equine practitioner. J. Eq. Med. Surg., v.1, p.87-94, 1977.

KLINGEL, H. Reproduction in the plains zebra, Equus burchelli boehmi: behaviour and ecological factors. J. Reprod. Fert., suppl. 6, p. 339-345, 1969.

MOHR, E. The Asiatic wild horse. London: J.A. Allen, 1971.

PONOMARENKO, N. The duration of embryonic development. Konev. Konnyi Sport, v.4, p.35-36, 1991.

ROPIHA, R.T.; MATTHEWS, R.G.; BUTTERFIELD, R.M. The duration of pregnancy in Thoroughbred mares. Vet. Rec., v.84, p. $552,1969$.

ROSSDALE, P.D. Abnormal behaviour in the Thoroughbred horse. In: FOX, M.W. Abnormal behaviour in animals. 2.ed. Philadelphia: W.B Saunders, 1968a.

ROSSDALE, P.D. Abnormal perinatal behaviour in the Thoroughbred horse. Br. Vet. J., v.124, p.540-553, 1968 b.
ROSSDALE, P.D.; RICKETTS, S.W. El parto. In: MEDICINA practica en el haras. 1.ed. Argentina: Hemisferio Sur S.A., 1979. p.172183.

ROSSDALE, P.D.; SHORT, R.V. The time of foaling of Thoroughbred mares. J. Reprod. Fertil., v.13, p.341-343, 1967

SENEDECOR, G.; COCHRAN, W. Statistical methods. 6.ed. Iowa State University, 1967. 593p.

TYLER, S.J. The behaviour and social organization of the New Forest ponies. Anim. Behav. Monogr., v.5, p.85-196, 1972.

UNANIAN, M.M. Eficiência na reprodução. Rev. Cavalo Árabe, v.10, p.80-81, 1991.

UNANIAN, M.M.; PEREIRA, A.C. Gestation and parturition in Thoroughbred and crossbred Arab horses. In: CONGRESSO BRASILEIRO DE REPRODUÇÃO ANIMAL, 9., 1991, Belo Horizonte. Anais... Belo Horizonte: CBRA, 1991. v.2, p.274. (Resumo).

VIVO, R.; CASTEJAN-CALDERON, F.J.; SANTISTEBAN, R. et al. Gestation length in Arab and Andalusian mares. Zootechny, v.33, p.263-267, 1984. 